\title{
Determinants of demand for total hip and knee arthroplasty: a systematic literature review
}

\author{
Rubén E Mújica Mota ${ }^{{ }^{*}}$, Rosanna Tarricone ${ }^{2}$, Oriana Ciani ${ }^{2}$, John FP Bridges ${ }^{3}$ and Mike Drummond ${ }^{4}$
}

\begin{abstract}
Background: Documented age, gender, race and socio-economic disparities in total joint arthroplasty (TJA), suggest that those who need the surgery may not receive it, and present a challenge to explain the causes of unmet need. It is not clear whether doctors limit treatment opportunities to patients, nor is it known the effect that patient beliefs and expectations about the operation, including their paid work status and retirement plans, have on the decision to undergo TJA. Identifying socio-economic and other determinants of demand would inform the design of effective and efficient health policy. This review was conducted to identify the factors that lead patients in need to undergo TJA.
\end{abstract}

Methods: An electronic search of the Embase and Medline (Ovid) bibliographic databases conducted in September 2011 identified studies in the English language that reported on factors driving patients in need of hip or knee replacement to undergo surgery. The review included reports of elective surgery rates in eligible patients or, controlling for disease severity, in general subjects, and stated clinical experts' and patients' opinions on suitability for or willingness to undergo TJA. Quantitative and qualitative studies were reviewed, but quantitative studies involving fewer than 20 subjects were excluded. The quality of individual studies was assessed on the basis of study design (i.e., prospective versus retrospective), reporting of attrition, adjustment for and report of confounding effects, and reported measures of need (self-reported versus doctor-assessed). Reported estimates of effect on the probability of surgery from analyses adjusting for confounders were summarised in narrative form and synthesised in odds ratio (OR) forest plots for individual determinants.

Results: The review included 26 quantitative studies-23 on individuals' decisions or views on having the operation and three about health professionals' opinions-and 10 qualitative studies. Ethnic and racial disparities in TJA use are associated with socio-economic access factors and expectations about the process and outcomes of surgery. In the United States, health insurance coverage affects demand, including that from the Medicare population, for whom having supplemental Medicaid coverage increases the likelihood of undergoing TJA. Patients with post-secondary education are more likely to demand hip or knee surgery than those without it (range of OR 0.87-2.38). Women are as willing to undergo surgery as men, but they are less likely to be offered surgery by specialists than men with the same need. There is considerable variation in patient demand with age, with distinct patterns for hip and knee. Paid employment appears to increase the chances of undergoing surgery, but no study was found that investigated the relationship between retirement plans and demand for TJA. There is evidence of substantial geographical variation in access to joint replacement within the territory covered by a public national health system, which is unlikely to be explained by differences in preference or unmeasured need alone. The literature tends to focus on associations, rather than testing of causal relationships, and is insufficient to assess the relative importance of determinants.

(Continued on next page)

\footnotetext{
* Correspondence: r.e.mujica-mota@exeter.ac.uk

${ }^{1}$ Institute for Health Services Research, University of Exeter, Veysey Building,

Salmon Pool Lane, Exeter, EX2 4SG, UK

Full list of author information is available at the end of the article
}

\section{Biomed Central}

(C) 2012 Mújica-Mota et al.; licensee BioMed Central Ltd. This is an Open Access article distributed under the terms of the Creative Commons Attribution License (http://creativecommons.org/licenses/by/2.0), which permits unrestricted use, distribution, and reproduction in any medium, provided the original work is properly cited. 
(Continued from previous page)

Conclusions: Patients' use of hip and knee replacement is a function of their socio-economic circumstances, which reinforce disparities by gender and race originating in the doctor-patient interaction. Willingness to undergo surgery declines steeply after the age of retirement, at the time some eligible patients may lower their expectations of health status achievement. There is some evidence that paid employment independently increases the likelihood of operation. The relative contribution of variations in surgical decision making to differential access across regions within countries deserves further research that controls for clinical need and patient lifestyle preferences, including retirement decisions. Evidence on this question will become increasingly relevant for service planning and policy design in societies with ageing populations.

Keywords: Orthopaedic implant, Arthroplasty, Hip, Knee, Demand, Need, Equity, Preferences, Patient selection, Osteoarthritis, Decision to operate, Socio-economic disparities, Total joint replacement

\section{Background}

Total hip arthroplasty (THA) and total knee arthroplasty (TKA) are effective for reducing pain and restoring the function and mobility of patients with severe arthritis [1]. In the United States from 1993 through 2005, TKA operations increased almost 2.5 times (from 200,216 to 497,419), while THA increased 1.7 fold (from 135,992 to $237,645)$. During the same period, the ratio of revisions to primary replacements decreased from $20 \%$ to $15.7 \%$ for THA, and from $9.2 \%$ to $8 \%$ for TKA [2]. In the UK, use of TKA rose, while THA remained stable over the period [3].

Changes in utilisation reflect an increasing need for surgery as a treatment for osteoarthritis (OA) derived from longer life expectancies, a rising elderly population, and an increased prevalence of obesity, which may also explain the faster increase of TKA relative to THA [4]. Improvements in devices, and in surgical and anaesthetic techniques, have widened the age range of patients eligible to receive these procedures [2,3].

These developments have taken place alongside observed utilisation differences by age, gender, and socio-economic status [5]. Such disparities warrant further research to establish the extent to which they reflect variations in disease risk or inequities in healthcare services $[5,6]$. In particular, women and individuals aged 70-80 are in greater need and have experienced larger increases in utilisation in recent years [3], but they face greater barriers to treatment access. Geographical barriers may also exist, as evidenced by the low rates of utilisation of deprived residential areas served by public healthcare systems [6] and variations in utilisation across areas of the United States [7,8].

According to their clinical training and field of medical specialty, health professionals may have differing views about whether a given person is a candidate for surgery $[9,10]$. Nevertheless, there is general agreement on some indications. For TKA, these include pain not controlled by medication and functional limitations, such as inability to walk at least one block [11]. As for contraindications, orthopaedists [12,13] and orthopaedic surgeons [14] cite some that include dementia and major psychiatric disorders, rheumatologists and orthopaedic surgeons name peripheral vascular disease $[11,14]$, and surgeons and orthopaedists refer to alcohol or drug abuse [4,12]. In addition, orthopaedic surgeons tend to agree that those younger than 55 and those with a physically demanding job are less likely candidates for TKA [14]. Less common contraindications for TKA include severe hip OA, quadriceps lag/weak quadriceps, obesity, and knee sepsis for more than a year [15].

Many patients who might otherwise benefit do not undergo surgery as a matter of preference [16,17]. It is critical to determine whether the decision to undergo surgery is systematically related to the underlying health of patients or to characteristics such as their socioeconomic status, which might determine their ability to benefit from and access surgery. Identifying the determinants of demand by those in need of surgery may inform planning for future orthopaedic resource needs, the design of interventions to address health inequities, and efficient targeting of resources.

The purpose of this paper is to report a systematic literature review that was conducted to identify the factors that lead patients in need to undergo THA or TKA. The review considered studies including patients who may be deemed eligible for elective surgery due to self-reported chronic pain, measured severity of disease, or doctor assessment, in order to ascertain the effect that clinical, demographic and socio-economic patient characteristics had on their probability of undergoing surgery or being recommended for surgery by doctors. Prospective and retrospective longitudinal and cross-sectional studies were considered for review.

\section{Methods}

An electronic search was undertaken in Medline (Ovid) and Embase up to 6 September 2011, using terms related to 'need,' 'decision to undergo surgery', and 'hip' or 'knee' replacement (see Additional file 1). The titles and abstracts were screened to identify studies of predictors 
of doctors' referral or recommendation for surgery, and patients' decisions to undergo surgery.

Studies were eligible for full-text review if they measured therapy utilisation while adjusting for need. The full text of studies reporting rates or likelihood of elective operations or measuring need or severity of illness were retrieved to ascertain whether rates of TJA receipt, offer or acceptance specific to individuals who might be eligible for surgery (on the basis of diagnosis of musculoskeletal condition, chronic pain, or functional limitations, or indicated as such by a health professional) had been reported and should therefore be considered for review. Studies that only presented rates on a per capita basis for the general population were excluded.

Studies of doctors' opinions about clinical characteristics or signs and symptoms in hypothetical patients were excluded unless they were validated against outcomes in actual patients. This restriction had the effect of excluding the literature on clinical and radiological opinion and health professionals' attitudes to risk and preference that, while relevant, would have added the complexity of reconciling stated with actual professional practice.

Exclusions also applied to reports of prevalence of need or of patients opinions' on surgery that had no subsequent analysis of predictors of incidence of operation or willingness to undergo surgery; trends in total number of hip or knee operations by providers or regions without account of patient need; preference elicitation studies in the general public; probability of surgery in any joints (combined with shoulder or other joints); healthcare consumption (e.g. costs) or indication (elective and non-elective) without specific reports for elective hip or knee surgery; and patient-doctor interaction studies without reference to a referral or operation decision. Quantitative studies with fewer than 20 patients were also excluded. References in the identified studies, were hand searched for additional relevant studies, which were screened according to the same process as applied to studies electronically searched.

A standardised form was used to extract information from included studies on study dates, place, setting, design and follow-up; objectives and sample characteristics; measured determinants associated with patients, doctors, setting or place; methods to adjust for confounding; and estimated independent effects of determinants (see Additional files 2, 3, 4, 5). Included studies were evaluated for the regional or national representativeness of their patient or clinician samples, and four attributes of internally valid observational analyses of demand determinants: prospective/longitudinal study and analysis; adjustment for socio-economic, clinical, and demographic confounders for estimating effects of determinants; use of both patient and doctor-assessed measures of need; and the reporting of attrition. For quantitative studies, each of these four elements of internal validity was rated as 1 if the requirement was met and 0 otherwise, and the overall sum across elements represented the quality score. Qualitative studies were not scored but were used to complement the information from quantitative studies. Screening of titles and abstracts, data extraction, and quality scoring were performed independently by two reviewers, who resolved their differences by discussion. The study protocol is available from the authors upon request (see Additional file 2 for PRISMA statement).

Given the heterogeneity of study designs and reporting practice in the literature, results from different studies were not synthesized quantitatively, but were presented in forest plots that made it possible to compare results across similar independent reports. The odds ratio (OR) and associated confidence interval (CI), the most commonly reported measure of effect, are presented for demand predictors. The review considered only ORs derived from (logistic) regression analyses that controlled for multiple covariates simultaneously. The major relative strengths or weaknesses of studies are noted, primarily in relation to the extent to which causal relationships may be inferred, and confounding discounted, from their results.

\section{Results}

The search yielded 2024 hits, for 1680 different records (923 in Medline and 757 in Embase). After the elimination of studies judged to be irrelevant because of their patient population (e.g., involving problems in joints other than hip or knee, sickle cell disease, osteonecrosis or malignancies), focus (e.g., health outcomes assessment, patient management practice alongside TKA or THA), scope (e.g., utilisation rates without accounting for patient need) or publication type (i.e., reviews and commentaries), 48 studies from Medline and an additional 23 studies from Embase remained (see Figure 1). Retrieval of full articles led to an additional 28 exclusions. A manual search through the bibliographies of the retrieved publications identified eight additional publications, six of which were included. In total, 49 publications were included in the review. Thirteen of these were extensions of initial studies and were thus reviewed together with the seminal study, constituting evidence on 36 distinct studies.

The studies were conducted in Australia, Canada (4), Denmark, France, Japan, The Netherlands, New Zealand, Spain (2), the UK (10), and the United States (14). Among these, 30 involved patients as subjects, whilst 6 studies included doctors. Three of the studies with doctors reported priority or referral algorithms.

In the studies on patients, need for total joint arthroplasty (TJA) was sometimes measured using standardised methods such as the WOMAC disease-specific 


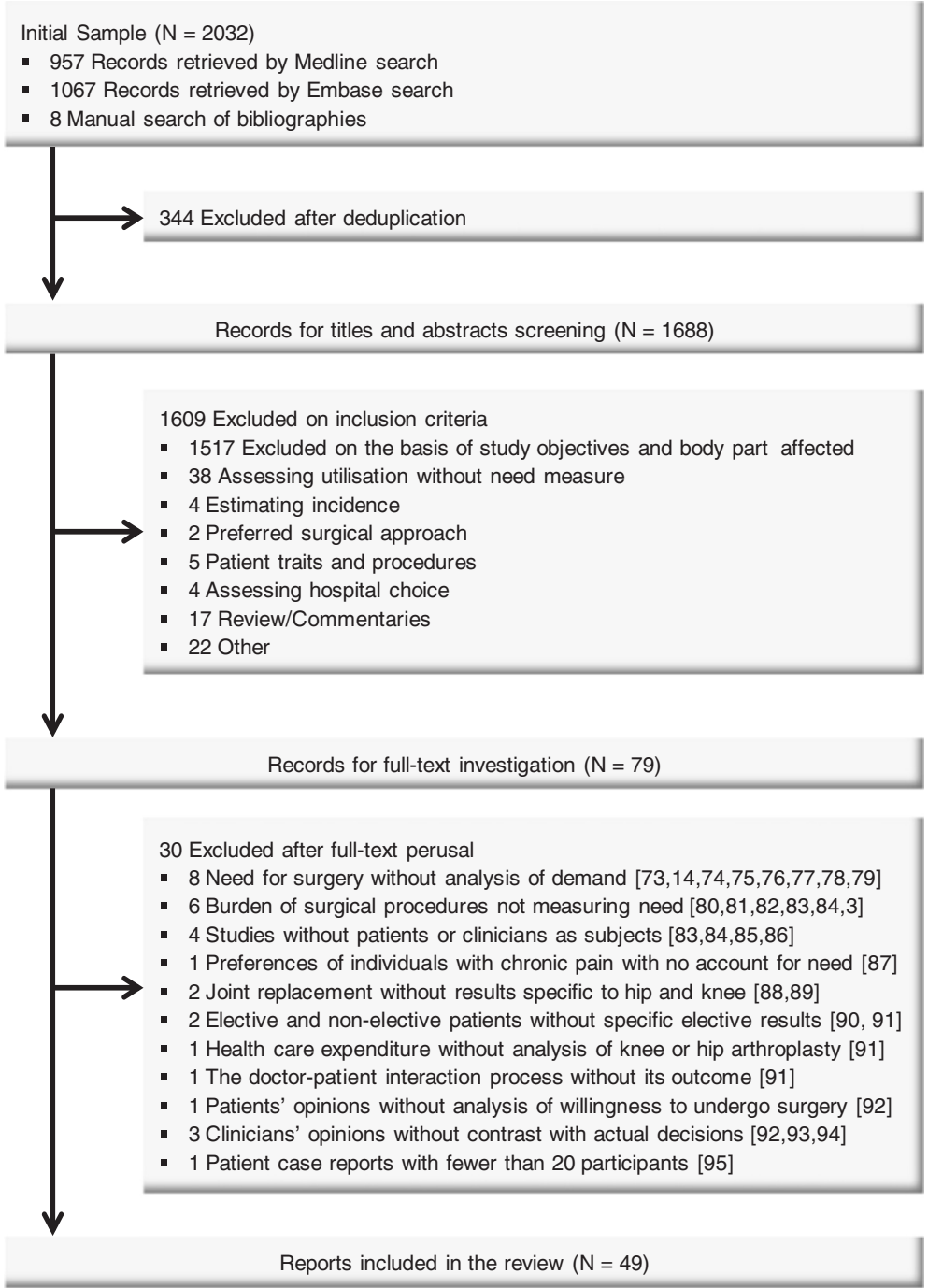

Figure 1 Process of identification of demand studies.

tool (5 studies), the Lequesne index (3), or the New Zealand score (3). In other studies, need was established through a self-reported condition or doctor diagnosis of arthritis, rheumatism, or arthritis-related visit to a doctor (3), diagnosis by a specialist physician (8), or chronic pain complaints or referrals to a specialist (7). The remaining study implicitly controlled for need by extrapolation using regression methods. Among the studies on patients, 7 were qualitative, 5 were quantitative assessments of patient views on surgery, 2 were concerned with willingness to change surgeons to reduce waiting time, and the remaining 16 were quantitative studies of factors behind receipt of surgery (see Additional file 3). Most of the studies included a mixed sample of retired and working-age individuals; only 4 of the quantitative studies involved mostly or exclusively patients older than 65 .

The quality scoring of quantitative studies (excluding the three studies on referral algorithms) is presented in Table 1. The overall scores are summarised in Table 2. Two studies, one related to doctors' decision making and one involving patients as subjects, met all the quality criteria for validity and were also potentially applicable to general practice. Three studies met only one out of four validity criteria. The majority of studies reported the effect of demographic characteristics on receipt of surgical treatment or willingness to consider or pay for surgery. Only 13 out of the 26 studies accounted for need based on a clinical evaluation or radiograph. Seven studies reported the effect of education, five studies that 
Table 1 Quality checklist

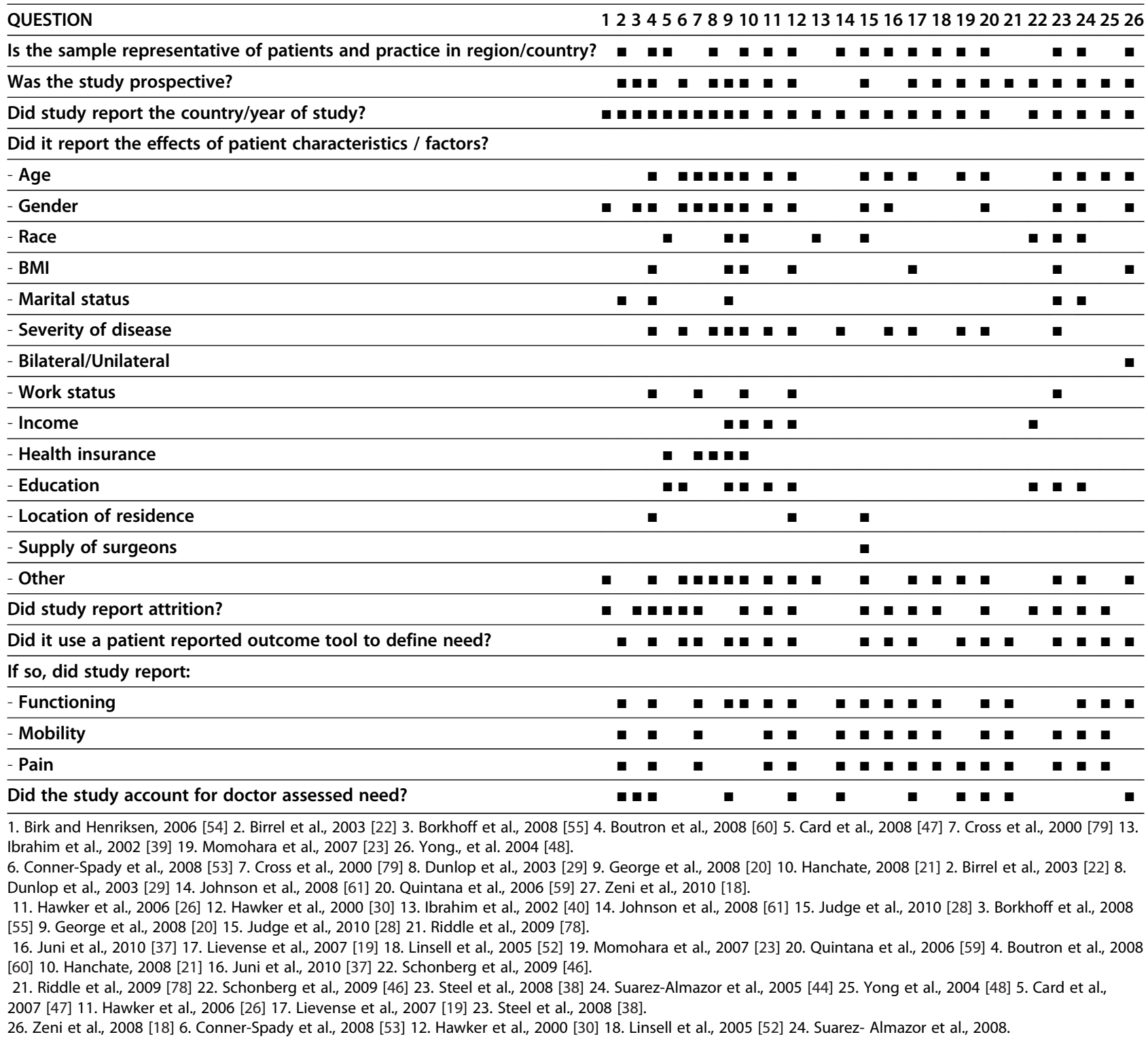

of health insurance, four that of income, and two reported on all three factors. The results are described in the next section, first for studies involving patients as subjects and then for those involving doctors.

\section{Studies on determinants of a patient's decision to undergo surgery \\ Clinical status and quality of life}

In end-stage knee OA (see Additional file 4, Additional file 5), patients with significantly weaker involved and uninvolved limbs, lower self-reported ability to function, or less knee extension were more likely to undergo TKA, whereas having bilateral as opposed to unilateral disease did not affect the probability of surgery [18]. Radiological information (Kellgren-Lawrence score greater than or equal to 2) and morning stiffness in a patient at an initial visit to a primary care doctor, each predicted his or her undergoing TKA within the subsequent three years. By six years after the initial visit radiological information, but not morning stiffness, predicted surgery (OR: 8.6; 3.0-24.6 [19]).

In patients with hip-related symptoms, difficulties with stooping and walking predicted primary THA within the following 3.5 years [20]. In addition to problems with getting up from a chair, climbing a flight of stairs, or crouching, stooping and walking difficulties each also predicted primary TKA within two years [21]. A diagnosis of cancer or diabetes reduced a patient's likelihood of 
Table 2 Summary of quality of identified quantitative studies

\begin{tabular}{|c|c|c|c|c|c|}
\hline Study (lead investigator) & Subjects & Joint & Question/End point & Score $^{*}$ & Generalisable \\
\hline Borkhoff $[55,56]$ & Primary care and surgeons & Knee & Referral & 3 & No(standardised cases) \\
\hline Boutron [60] & Primary care doctors & $\begin{array}{l}\text { Knee and } \\
\text { hip }\end{array}$ & Referral & 4 & Yes \\
\hline Quintana [57-59] & Specialists & $\begin{array}{l}\text { Knee and } \\
\text { hip }\end{array}$ & Recommendation & 3 & Yes \\
\hline Birk [54] & Waiting list patients & $\begin{array}{l}\text { Knee and } \\
\text { hip }\end{array}$ & Decision to change surgeon & 2 & No \\
\hline Birrell [22] & Primary care patients & Hip & Waiting list placement & 2 & Yes \\
\hline Card [47] & Older adults & $\begin{array}{l}\text { Hip and } \\
\text { knee }\end{array}$ & Arthroplasty & 2 & Yes \\
\hline Conner-Spady $[27,53]$ & Waiting list patients & $\begin{array}{l}\text { Knee and } \\
\text { hip }\end{array}$ & Hypothetical change of surgeon & 3 & No \\
\hline Cross [79] & Operated patients & $\begin{array}{l}\text { Knee and } \\
\text { hip }\end{array}$ & Willingness to pay & 3 & No \\
\hline Dunlop [29] & Older adults & $\begin{array}{l}\text { Knee and } \\
\text { hip }\end{array}$ & Arthroplasty & 2 & Yes \\
\hline George [20] & OA Medicare patients & Hip & Arthroplasty & 3 & No \\
\hline Hanchate [21] & Older adults & Knee & Arthroplasty & 3 & Yes \\
\hline Hawker [26] & OA patients & $\begin{array}{l}\text { Knee and } \\
\text { hip }\end{array}$ & Arthroplasty & 4 & Yes \\
\hline Hawker [30-33] & OA patients & $\begin{array}{l}\text { Knee and } \\
\text { hip }\end{array}$ & Willingness to operate & 3 & Yes \\
\hline Ibrahim [39-42] & Primary care males VA patients & $\begin{array}{l}\text { Knee and } \\
\text { hip }\end{array}$ & Willingness to operate & 1 & No \\
\hline Johnson [61] & Primary care patients & Hip & Waiting list placement & 1 & Yes \\
\hline Judge [28] & Older adults & $\begin{array}{l}\text { Knee and } \\
\text { hip }\end{array}$ & Arthroplasty & 2 & Yes \\
\hline Juni $[36,37]$ & Primary care patients & $\begin{array}{l}\text { Knee and } \\
\text { hip }\end{array}$ & $\begin{array}{l}\text { Waiting list placement/ } \\
\text { Willingness to operate }\end{array}$ & 1 & Yes \\
\hline Lievense [19] & Primary care patients & Hip & Arthroplasty & 2 & Yes \\
\hline Linsell [52] & Retirement age adults & $\begin{array}{l}\text { Hip and } \\
\text { knee }\end{array}$ & Willingness to operate & 2 & Yes \\
\hline Momohara [23] & RA patients & Knee & Arthroplasty & 2 & Yes \\
\hline Riddle [78] & OA patients & Knee & Arthroplasty & 2 & No \\
\hline Schonberg [46] & Retirement age OA patients & $\begin{array}{l}\text { Knee and } \\
\text { hip }\end{array}$ & Referral & 2 & No \\
\hline Steel [38] & OA/RA patients & $\begin{array}{l}\text { Knee and } \\
\text { hip }\end{array}$ & Arthroplasty & 3 & Yes \\
\hline Suarez-Almazor $[44,45]$ & OA patients & Knee & Willingness to operate & 3 & Yes \\
\hline Yong [48] & Non-obese retirement age adults & Knee & Arthroplasty & 2 & No \\
\hline Zeni [18] & OA patients & Knee & Arthroplasty & 2 & Yes \\
\hline
\end{tabular}

*Sum of individual internal validity criterion rating ( 1 = study met criterion; 0 otherwise; maximum score: 4$)$. Criteria: Prospective/longitudinal study and analysis; adjustment for confounding; reporting of attrition; doctor-assessed need.

undergoing surgery, whereas diagnoses of heart disease, lung disease, or high blood pressure had no effect [21].

In a UK study, a scoring system comprising radiological parameters (internal rotation), hip pain severity, and the use of a walking stick enabled researchers to correctly identify $76 \%$ of primary care patients who were put on a waiting list for surgery, and $95 \%$ of those that were not, after 3 years [22]. Pain severity and functional disability were also independently, positively associated with primary TKA over a 5-year follow-up period in RA patients [23]. Pain is the single most important influential factor in the decision to undergo knee and hip arthroplasty [24], although patients define their need in terms of a doctor diagnosis based on $\mathrm{x}$-ray test results [25]. Patients with test scores indicating more severe arthritis (WOMAC), or higher health status (SF-36 General Health score), were predisposed to undergo primary TKA or THA [26], while patients with higher quality of life scores 


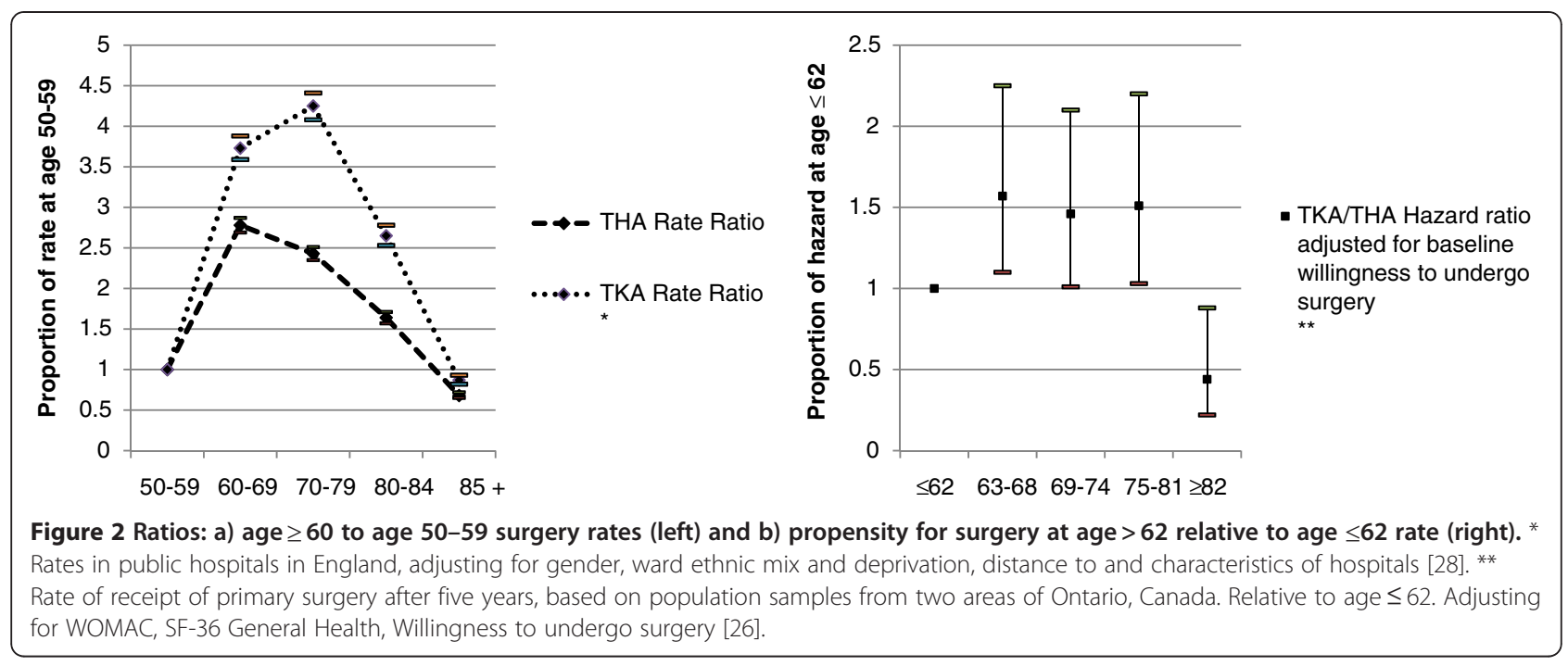

(EuroQol 5-Dimension, EQ-5D; see Additional file 5) expressed less willingness to change surgeons in order to reduce operation waiting time [27].

\section{Age}

Age is a complex factor in predicting whether patients will undergo TJA, since their willingness to do so can depend on their expectations of functionality, which change with age. Among a group of patients visiting their primary care doctor with chronic hip pain, those aged 60 years or older were more likely to undergo THA within three and six years [19]. In England, the rate of surgery has been observed to increase with age to a peak at 60-69 for THA, and at 70-79 for TKA, before declining to a nadir at age $\geq 80$ [28]. Likewise for the United States, octogenarians have reportedly lower rates for primary THA [20], and for TKA or THA overall [29]. That patients aged 62 years or younger and those in their eighties are less likely to receive TJA is confirmed by the only study that controlled for willingness to undergo surgery (and, implicitly by its taking place in a public health system, for economic access), which also found no apparent variation in the incidence of TKA or THA among those in the age range from 63 to 81 [26] (Figure 2b). In fact, a precursor to the study had found those older than 65 to be less willing to operate [30-33]. Studies from the United States have discrepant results, suggesting greater use after age 60, which in two cases may be difficult to interpret since the studies controlled neither for health insurance status nor income $[18,19]$. On the other hand, the third was the only instance of a study controlling for employment status and economic access (i.e., health insurance), and found that individuals under 65 were less likely to undergo TKA than older

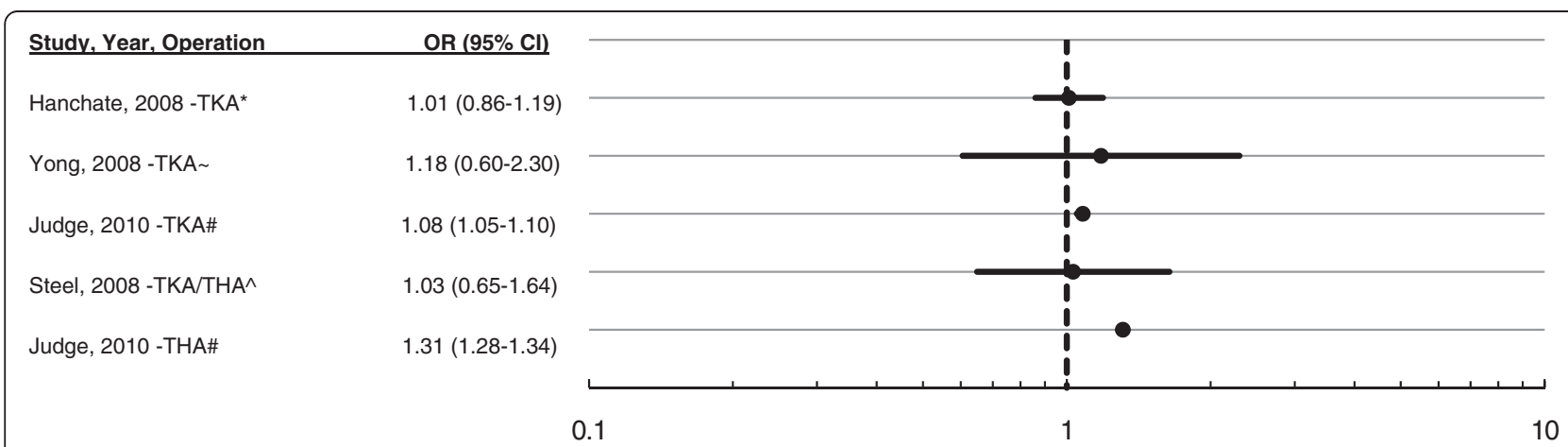

Figure 3 Ratio of male to female surgery rate. *U.S. population-based study age $\geq 47$. Patients with an arthritis-related visit to the doctor in the past two years at baseline. Adjusted for age, gender, race, comorbidities, functional limitations, income, wealth, insurance type, employment, and $\mathrm{BMI} \geq 25$ [21]. Rate over 18 months, from south of England study of patients aged $\geq 65$. Unadjusted for confounders [48]. \#Surgical rates in public hospitals, population of England. One year incidence, adjusted for socio-economic and ethnicity mix of ward of residence [28]. $\wedge$ Respondents reporting an arthritis-related visit at baseline. Adjusting for demographics, health need and economic access (including health insurance, wealth and education) [38]. 
adults (OR: 0.72; 0.52-1.01) [21]. Thus, while functional expectations and perceived need vary inversely with age $[25,34]$, it appears that some of the lower utilisation rates of the youngest and oldest patients in need (Figure 2a) are due to limited access to surgery [34].

\section{Gender}

Women view unmet functional needs as primarily associated with walking and shopping limitations, whereas men discuss their effects on leisure activities [25]. Women older than 54 experienced higher levels of unmet need for arthroplasty, but had lower rates of surgery than men of the same age. While more likely to seek treatment for their arthritis given similar self-reported comorbidities, women were less likely to have discussed the option of arthroplasty with a primary care doctor [30-33]. Contrary to reports that women are more risk averse and undergo surgery later [35-37], no gender difference was found in terms of willingness to undergo treatment, which predicted surgery within five years [26]. These results led researchers to propose the doctor-patient interaction as the source of barriers to surgery [30-33].

Gender had no effect on patient receipt of primary TKA or THA in Toronto, Canada [26], or in the United States $[18,20]$. Similarly, gender did not affect the two-year rates of respondents to the U.S. Health and Retirement Study (HRS) [21,38] or among members of an elderly cohort [29]. Only one study reports a gender differential: underutilisation by women that is larger in the more deprived districts of England (Figure 3) [28]. However, the study's limited control for confounders, relying as it does on deprivation and ethnicity mix measures at the ward level to proxy individual respondent socio-economic status, casts doubt on the validity of its findings (Additional file 4). As for waiting-list patients, men have been more likely than women to respond affirmatively to a hypothetical question about changing to an equally qualified surgeon with a shorter waiting time [27].

\section{Race}

Evidence on this factor was found only for the United States (Figure 4). There are documented disparities in two-year rates of hip and knee surgery for arthritis between blacks (2\% per year), Hispanics (1.79\%), and whites $(4.35 \%)$ in a national cohort of persons older than 69 [29] that are robust to adjustment for demographic, health, and economic access factors, including health insurance. Together with results on hip and knee surgery for HRS respondents older than 59 [38], these findings suggest that ethnic minorities have lower utilisation of TJA independent of access factors.

In addition to differences in disease severity, comorbidity, and socio-economic characteristics, minorities also have a lower willingness to undergo the operation. This inclination is due to lower expectations of surgical efficacy and less familiarity with the operation among African Americans, who are less likely to know someone treated with arthroplasty, more likely to think it involves extended hospitalisation and recovery and more likely to have concerns about possible outcomes (Figure 4, bottom half) [39-45]. Nevertheless, severe OA patients aged 65 and older who discussed surgery with their primary care doctors were more likely to undergo surgery in the following year, and the likelihood of having such a discussion did not differ between white and non-white

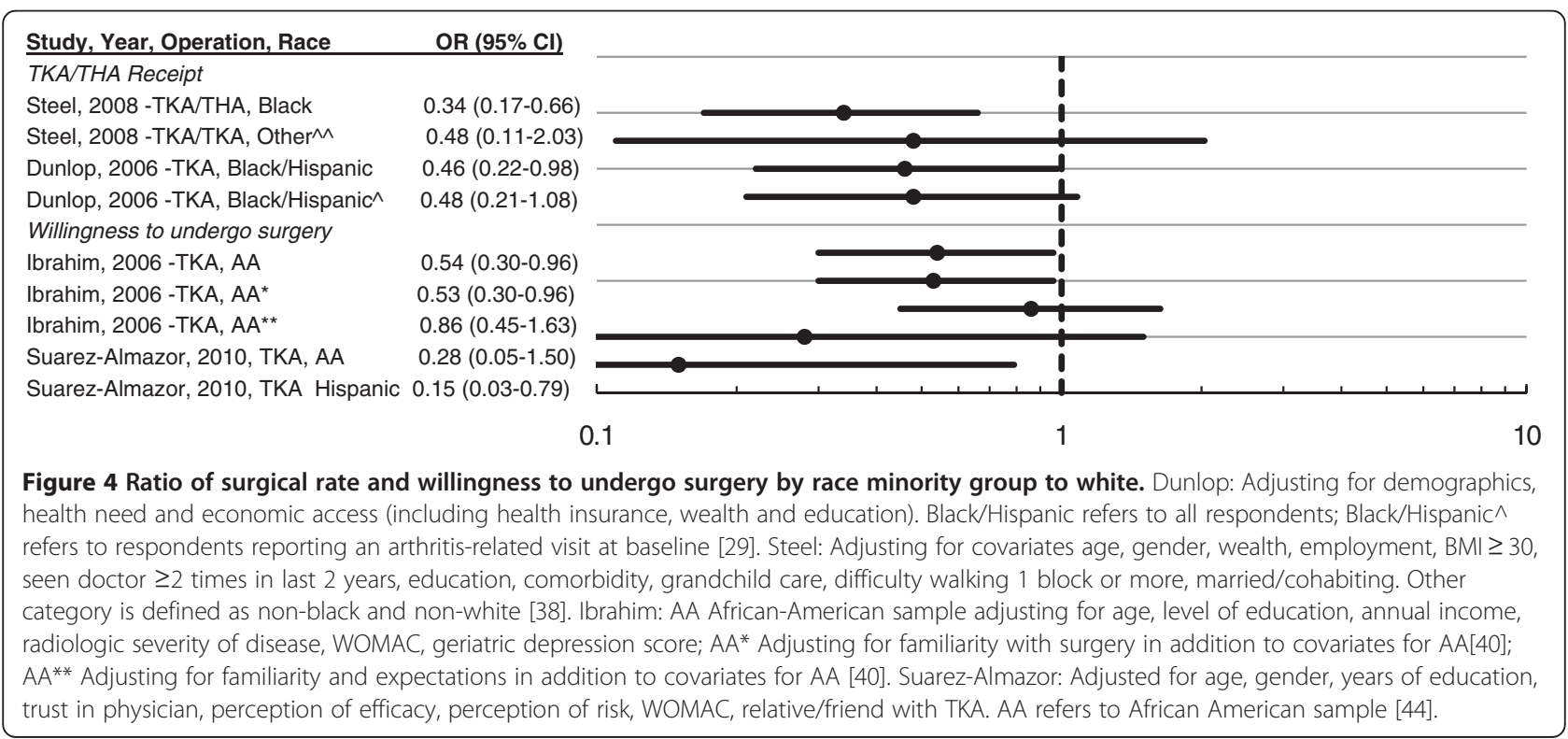


Table 3 Specialist referral and waiting list prioritisation instruments, levels and scores for THA and TKA

\begin{tabular}{|c|c|c|c|c|c|c|c|c|}
\hline \multicolumn{3}{|c|}{ CAHTA* } & \multicolumn{3}{|c|}{ CPAC** } & \multicolumn{3}{|c|}{ WCWLP*** } \\
\hline Criteria & Level & Score & Criteria & Level & Score & Criteria & Level & Score \\
\hline \multirow{11}{*}{$\begin{array}{l}\text { Severity of disease } \\
\text { (clinical and radiological } \\
\text { exploration) }\end{array}$} & Moderate & 0 & Pain on examination & None & 0 & & & \\
\hline & Severe & 18 & & Mild & 6 & & & \\
\hline & & & & Moderate & 15 & & & \\
\hline & & & & Severe & 30 & & & \\
\hline & & & \multirow[t]{4}{*}{ Other abnormal findings } & None & 0 & \multirow{4}{*}{$\begin{array}{l}\text { Abnormal findings on } \\
\text { physical exam }\end{array}$} & None/mild & 0 \\
\hline & & & & $\overline{\text { Mild }}$ & 2 & & Moderate & 5 \\
\hline & & & & Moderate & 5 & & Severe & 9 \\
\hline & & & & Severe & 10 & & & \\
\hline & & & \multirow[t]{3}{*}{ Multiple joint involvement } & No & 0 & & & \\
\hline & & & & $\begin{array}{l}\text { Yes, affected joints with } \\
\text { moderate severity }\end{array}$ & 4 & & & \\
\hline & & & & Yes, severe involvement & 10 & & & \\
\hline \multirow[t]{6}{*}{ Pain } & Mild & 0 & \multirow[t]{6}{*}{ Degree of pain } & None & 0 & \multirow[t]{5}{*}{ Pain on motion } & None/mild & 0 \\
\hline & Moderate & 17 & & Mild & 4 & & Moderate & 13 \\
\hline & \multirow[t]{4}{*}{ Severe } & \multirow[t]{4}{*}{33} & & Mild to moderate & 6 & & Severe & 20 \\
\hline & & & & Moderate & 9 & & & \\
\hline & & & & Moderate to severe & 14 & & & \\
\hline & & & & Severe & 20 & Pain at rest & & \\
\hline \multirow[t]{2}{*}{ Probability of recovery } & Moderate & 0 & & & & & & \\
\hline & High & 4 & & & & & & \\
\hline \multirow[t]{10}{*}{ Difficult in doing $A D L$} & Some difficulty & 0 & \multirow[t]{6}{*}{ Time walked } & Unlimited & 0 & \multirow{6}{*}{$\begin{array}{l}\text { Ability to walk without } \\
\text {-significant pain }\end{array}$} & Over 5 blocks & 0 \\
\hline & Great difficulty & 10 & & $31-60 \mathrm{~min}$. & 2 & & $1-5$ blocks & 4 \\
\hline & \multirow{8}{*}{$\begin{array}{l}\text { Unable to do } \\
\text { most ADL }\end{array}$} & \multirow[t]{8}{*}{20} & & $11-30 \mathrm{~min}$. & 4 & & Less than 1 block & 8 \\
\hline & & & & 2-10 min. & 6 & & Household ambulatory & 13 \\
\hline & & & & $2<\min$. or indoors only & 8 & & & \\
\hline & & & & Unable to walk & 10 & & & \\
\hline & & & \multirow[t]{4}{*}{ Other functional limitations } & None & 0 & \multirow{4}{*}{$\begin{array}{l}\text { Other functional } \\
\text {-limitations (ADL) }\end{array}$} & None & 0 \\
\hline & & & & Mild & 2 & & Mild & 2 \\
\hline & & & & Moderate & 4 & & Moderate & 4 \\
\hline & & & & Severe & 10 & & $\begin{array}{l}\text { Severe (unable to do } \\
\text { most activities) }\end{array}$ & 10 \\
\hline
\end{tabular}


Table 3 Specialist referral and waiting list prioritisation instruments, levels and scores for THA and TKA (Continued)

\begin{tabular}{|c|c|c|c|c|c|c|c|c|}
\hline \multirow{2}{*}{$\begin{array}{l}\text { Limitation on ability } \\
\text { to work }\end{array}$} & No/does not work & 0 & \multirow{3}{*}{$\begin{array}{l}\text { Ability to work, give care to } \\
\text {-dependents or live } \\
\text { independently }\end{array}$} & Not threatened & 0 & \multirow{6}{*}{$\begin{array}{l}\text { Ability to work, give } \\
\text { care to dependents } \\
\text {-or live independently }\end{array}$} & \multirow{2}{*}{$\begin{array}{l}\text { Not threatened but } \\
\text { more difficult }\end{array}$} & \multirow[t]{2}{*}{0} \\
\hline & Yes & 10 & & & & & & \\
\hline \multirow[t]{2}{*}{$\begin{array}{l}\text { Has someone to look } \\
\text { after the patient }\end{array}$} & Yes & 0 & & $\begin{array}{l}\text { Not threatened but } \\
\text { more difficult }\end{array}$ & 4 & & $\begin{array}{l}\text { Threatened but } \\
\text { not immediately }\end{array}$ & 7 \\
\hline & No & 9 & & \multirow{2}{*}{$\begin{array}{l}\text { Threatened, but not } \\
\text { immediately }\end{array}$} & \multirow[t]{2}{*}{6} & & \multirow[t]{3}{*}{ Immediately threatened } & \multirow[t]{3}{*}{10} \\
\hline \multirow[t]{2}{*}{ Be a care-giver } & No & 0 & & & & & & \\
\hline & Yes & 6 & & Immediately threatened & 10 & & & \\
\hline
\end{tabular}

*Catalan Agency for Health Technology Assessment [62]; **Clinical Priority Assessment Criteria [63].***Western Canada Waiting List Program [65] (asks about situation over the past three months). 


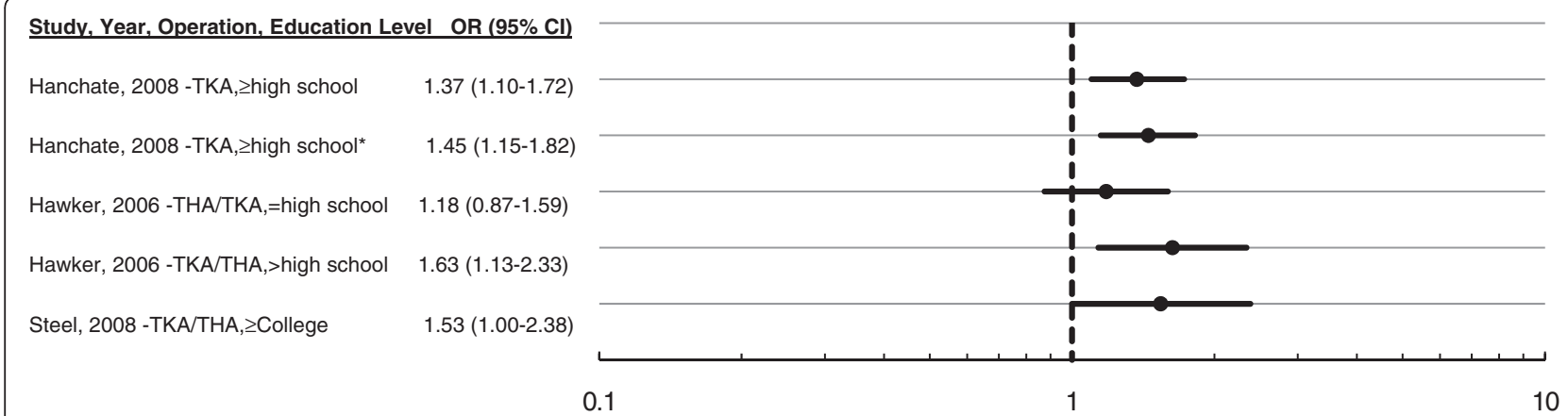

Figure 5 Ratio of surgical rate with post-secondary education to rate with lower education level. Hanchate: Relative to less than high school education. U.S. population-based study age $\geq 47$. Adjusted for age, gender, race, comorbidities, functional limitations, income, wealth, insurance type, employment, BMI $\geq 25$. *Refers to respondents with an arthritis-related visit to the doctor in the past two years at baseline; other result refers to all respondents [21]. Hawker: Relative to less than high school education. Sample from two areas in Ontario, Canada. Adjusting for WOMAC, SF-36 General Health, age [26]. Steel: Relative to less than college education. U.S. population-based study age $\geq 60$. Adjusting for covariates age, gender, wealth, employment, $\mathrm{BMI} \geq 30$, seen doctor $\geq 2$ times in past 2 years, comorbidity [38].

patients once the effects of education and income were accounted for [46].

\section{Education}

Three studies report the effect of education on the probability of surgery. Post-secondary education is associated with higher likelihood of primary surgery, whether to treat knee OA [21], knee or hip OA [38], or for patients in need of primary TKA or THA surgery (Figure 5) [26]. On the other hand, a study among 198 OA patients in the United States found that education had no effect on the probability of considering TKA in the event of the knee arthritis worsening and the doctor recommending surgery, by controlling for perception of efficacy and race [44]. Other U.S. studies of TKA or THA and of THA [20,29], report 'statistically insignificant' results without providing the estimates. Post-secondary education has also been positively associated with patients' willingness to change surgeons in order to reduce their waiting time for surgery (OR: 1.73, 1.15-2.62 [27]).

\section{Income/health insurance}

In the United States, lack of health insurance under the age of 65, low household income per cohabitant, and household assets below $\$ 5,000$ (in 1998 prices) were independently associated with low TKA use [21]; by the age of full retirement, health insurance and multiple insurance plans increased the likelihood of TKA or THA [47]. Supplemental health insurance also increased operation rates in the Medicare population (OR: 0.46; 0.220.95)[29]. In Toronto, Canada, where universal public health insurance exists, income had no effect on primary TKA or THA, after adjusting for education [26]. By

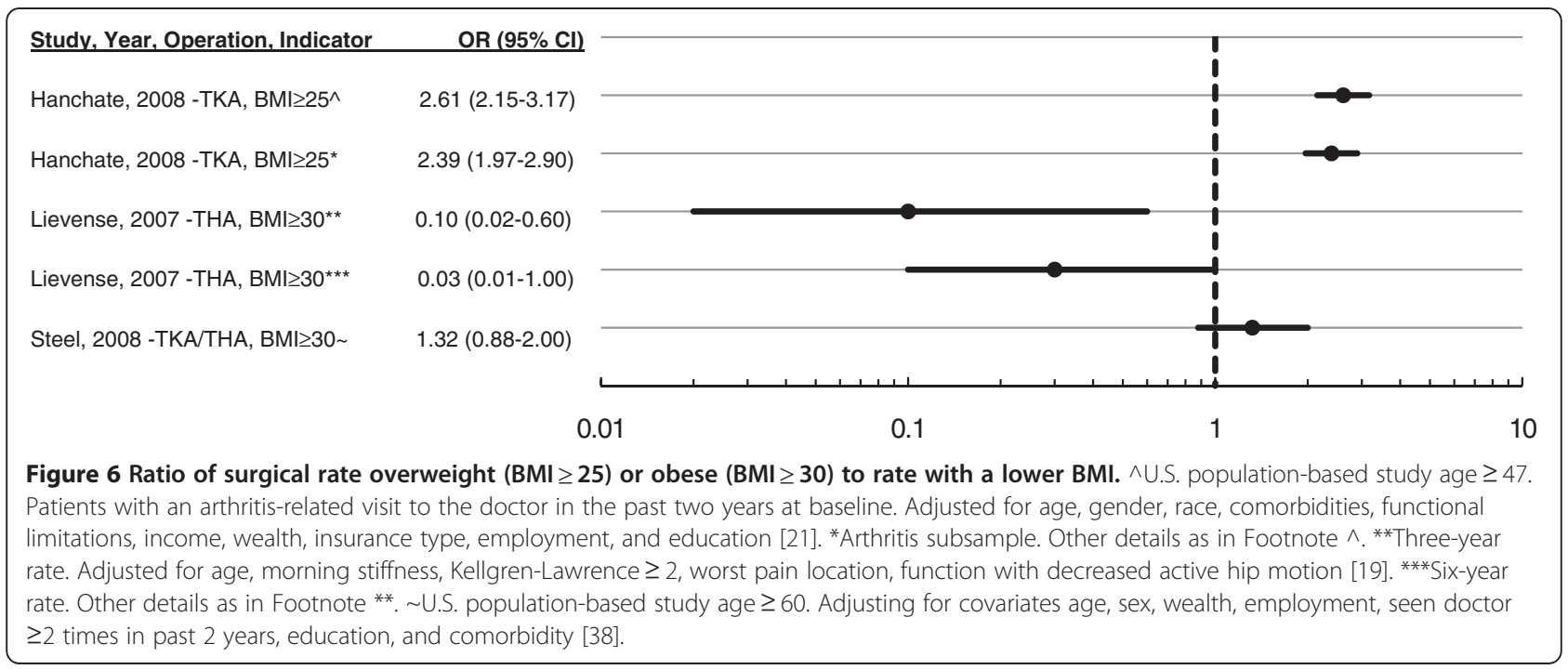


contrast, low income was associated with a low probability of patients in northeast England having gone through surgery within 18 months of their initial visit to a primary care doctor with a complaint of knee pain [48], but this evidence is of limited value since the study failed to control for confounders.

\section{Employment}

Using HRS data for the period 1996-2004, Hanchate and colleagues [21] estimated a higher two-year incidence of TKA with current employment relative to no employment (OR: 1.28; 1.04-1.58), after adjusting for relevant confounders, including age under 65. A separate independent analysis of the probability of TKA or THA, among HRS respondents older than 59 during the period 1998-2004 resulted in a similar but imprecise estimate (OR: 1.29; 0.74-2.25)[31], which also differed from the first analysis in its lack of adjustment for health insurance status. Paid employment had no independent effect on time to first TKA or THA in an Ontario, Canada, cohort of persons with OA aged 55 and older [26].

\section{Other Factors}

Caring responsibilities may discourage eligible older patients from taking up arthroplasty [30]. Self-awareness of weight problems has also been found to discourage patients from undergoing surgery [34]. Furthermore, being overweight or obese appears to reduce the likelihood of subsequent use of THA [19], although it does not have the same effect on use of TKA [21,38] (Figure 6).

When assessing suitability for surgery, specialists take into consideration the patients' preferences on leisure activities, as well as work, and family life circumstances, including cohabitation [49]. Those waiting for TKA often worry about becoming reliant on family and friends for their daily activities [25], and women have recorded higher levels of unmet need and disability than men, primarily because proportionally more of them live alone [30]. By contrast, one study found that the civil status of Medicare OA patients had no effect on their probability of undergoing primary THA [20]; however, the result may have lacked statistical power.

Hip and knee OA patients who end up being referred to specialists either seek care early on with the view toward preventing their disease from becoming worse or wait until symptoms become unbearable to seek treatment $[45,50]$. Their decisions to undergo surgery are prompted by increasing severity of limitations that affect their basic quality of daily living, relationships, and psychological well-being [51]. Contrary to other independent results [52], an analysis controlling for race and perceived severity found that having a friend or relative who had undergone TKA had no effect on the willingness of persons with knee OA to consider surgery. However, this result and the equally absent evidence of effect for perceived risk level [44] may be due to the small size of the respective study $(\mathrm{n}=198)$.

Indeed, qualitative evidence suggests that patients are susceptible to influence from the negative surgical experiences of other persons [30,45], and that their preferences on TKA are also influenced by previous personal experience of surgery, including non-orthopaedic types of surgery [45]. In southern England, individuals with chronic knee pain were more likely to have consequently sought treatment from their GP than were persons with chronic hip pain, and were less [36] or equally likely [52] to have been referred to and seen a specialist. In these studies, knowing others who had had surgery was associated with positive attitudes about surgical success and TKA patients had fewer such acquaintances than THA ones did.

Differences in healthcare access between hip and knee patients have occurred at the referral stage in both primary [36] and secondary care [52]. Moreover, across English districts, a study has reported replacement rate variations from 1.22 to $14.4 \%$ for hips and from 1.05 to $6.19 \%$ for knees. While rural areas tended to have greater use of hip replacement, knee replacement was more common in urban settlements [28]

Studies of hypothetical choices, in Canada [27,53], and actual decisions, in eastern Denmark [54], found that, when patients were presented with the opportunity to change surgeons of comparable quality in order to undergo surgery earlier, 50--60\% of patients declined it. Having an expressed preference for a specific doctor reduced the odds of changing surgeons by $43 \%$, while having a certain date of operation dominated waiting time considerations.

Patients who declined re-referral from a local hospital to one beyond their county of residence also declared the longer distance and transport time as main reasons for their decision [54].

\section{Studies with surgeons and general practitioners}

In a study in Ontario, Canada, prior discussion of TKA or THA with a physician emerged as the driver of patient willingness to consider surgery [30]. Hypotheses about gender disparities in the contents of such patientdoctor interactions [30] are supported by results from another Canadian study of GPs and orthopaedic surgeons' blinded referrals or recommendations of TKA for two standardised moderate knee OA patients who differed only in gender $[55,56]$. GPs referred men to specialists 1.3 times as often as they referred women, while surgeons were nine times as likely to recommend surgery to men as they were to women. On the other hand, 
a cross-sectional study in the United States found no differences in the likelihood of a physician recommendation of surgery across ethnic groups after adjusting for age, gender, education and disease severity [44]. Consistent with these results, in a study in 40 general practices in southwest England, their referrals to specialists, consultations with orthopaedists, and waiting list assignments for hip replacements were less frequent for women than for men. These findings were robust to adjustments for willingness to undergo surgery and other covariates, despite the fact that no differences between genders had been found in patients' access to drug therapy for chronic hip pain [37]. In this regard, it is worth noting that doctors rely on non verbal signs, such as perceived tiredness suggestive of severe night pain, or anxiety in a patient attending consultation, to decide on the manner and timing of communicating information about surgical risk [49].

As for health specialist opinions, the likelihood of classifying an individual THA case as appropriately referred was most influenced by pain and, secondly, by functioning; bone quality was of marginal significance [57]. Six months after THA, patients classified as 'appropriate' and 'uncertain' had lower complication and mortality rates, and similarly higher improvements in the physical and pain domains of the SF-36 and the three dimensions of the WOMAC than patients classified as inappropriate'. For classifying TKA patients, symptoms took precedence, followed by radiological evidence, mobility, age, previous surgical management, and localisation [58]. 'Appropriate' TKA referral patients saw greater gains in the social function score and the three WOMAC dimensions than 'inappropriate' patients $[57,59]$.

In France, a GP's opinion that an OA patient would need surgery within the following 12 months was primarily determined by clinical factors, with severity of disease the most influential determinant. Cases analysed in this study had more days with pain, were more disabled (Lequesne and WOMAC; Additional file 3), and had lower levels of health-related quality of life (SF-36 PCS and MCS; Additional file 5) than other patients. They were more likely to live in a rural environment, often male, older, and took medication for OA more often. The only determinant that varied between hip and knee conditions was gender, which affected only hip patients [60].

In England, an Oxford Hip Score greater than or equal to 34 and radiographic evidence of a complete loss of joint space or severe marginal osteophyte formation together correctly predicted $87.5 \%$ of cases deemed by surgeons to require THA and $50 \%$ of cases deemed not to require THA [61]. Prioritisation of patients for surgery based on doctors' opinions moderately reflected the views of patients about the difficulty caused by their condition, while strongly reflecting the views of orthopaedic surgeons about their patients' priority for surgery (see Table 3 [62]). Priority is given to those with severe clinical and radiological disease, more severe pain, high probability of recovery, greater difficulty in performing activities of daily living, and to patients affected in their ability to work, without a caregiver, and with caring responsibilities for another person. Among general practitioners, similar assessments are used for rationing in New Zealand [63,64] and Canada [65].

A study of English general practitioners by Linsell and colleagues documents lower utilisation of $\mathrm{x}$-ray tests and similar referral rates for primary care patients with chronic knee pain relative to patients reporting hip pain [52]. Consequently, the authors argue that GPs in Oxfordshire, appear to follow national guidelines, which state that knee OA is best diagnosed clinically, contrary to the recommended practice for hip OA [66]. However, there are examples where the availability of radiological information determined the likelihood of referral to specialists in both hip and knee patients [19,22]. Moreover, in-depth interviews of specialists have revealed that the decision to offer surgery involves "various judgements and skills derived from experience" which are partly "instinctive and partly informed by the literature" [49].

\section{Discussion}

This review summarises the evidence on determinants of hip and knee replacement in patients eligible for the operation. Across all the studies assessed for this review, the likelihood of a patient receiving arthroplasty depended mostly on clinical characteristics of the joint, physician recommendations, patients' perceptions and preferences, and interactions between doctors and their patients. In public health systems, willingness to undergo surgery was the most important determinant of receipt, implying that the effect on surgery receipt of patient characteristics represents primarily behavioural variation by patients rather than by doctors acting on their behalf. Underpinning demand for THA and TKA were education and, in the United States, possession and extent of health insurance coverage.

Some studies analyse predictors of surgery without accounting for socio-economic determinants, which are particularly important in health systems without universal public healthcare [32]. Socio-economic differences account for most of the gender- and age-related variations in utilisation, but not for those related with race. In the United States -the only country for which the question of racial disparities was addressed- racial minorities were less willing to undergo surgery due to their low expectations for surgical outcomes. Such differences in expectations appear to be determined by social networks [67] and culture surrounding minority groups, 
and point to questions about the quality of healthcare available to them [68]. These observations, together with the reviewed evidence on larger gender-related gaps in more deprived regions of England, suggest that underutilisation of healthcare technology may be socially, economically, and culturally determined.

The age of prospective patients may have an impact on their willingness to undergo surgery. In the range from 50 to 70 years of age, patients' willingness appears to decline with increasing age. However the extent to which this effect depends on retirement opportunities of patients or their partners or availability of informal care by friends and relatives is unclear, as no study has addressed the issue. One study reports an association between TKA receipt and employment suggesting that TKA is valued more by persons engaged in paid work than by other individuals with the same socio-economic status, health insurance type, education, disease, health status, and demographic characteristics [21]. A second study, found the same magnitude of effect on TKA or THA but, unlike the first, was confounded by the lack of adjustment for health insurance status [38]. Since health insurance in the United States is positively correlated with arthroplasty [47] and negatively correlated with employment two years subsequently [69], the study is likely to underestimate the combined effect on THA or TKA, thus suggesting that employment has a stronger effect on THA than that reported for TKA [21]. Further research is warranted to establish whether a causal relationship running from employment to TJA use exists. If so, additional analysis may be required to understand whether the nature of such relationship originates from economic incentives for patients to demand healthcare [70], or inducement by doctors [71,72]-as would be the case, for example, if surgeons in the United States were to be more inclined to recommend surgery to VA members with supplementary insurance than to those with only VA coverage [42]. A third paradigm would consider also the influence on decision making of social norms and identities [73].

Studies on clinicians' views have found that primary care doctors and orthopaedic surgeons hold different opinions about patient eligibility for surgery [10]. Primary care doctors generally want patients to meet higher thresholds of disease severity than those required by orthopaedic surgeons. It has been suggested that primary care doctors may lack adequate information about the risks and benefits of total joint replacement, and may therefore inadvertently restrict access to healthcare [2]. Nevertheless, the decisions of primary care doctors about relative healthcare service use and referrals in the south of England were found to be consistent with OA management guidelines, which recommend that patients with knee pain be diagnosed on the basis of clinical rather than radiological evidence [52]. These guidelines for managing patients with knee symptoms are contrary to the guidelines for managing patients with hip symptoms, but there is evidence that radiographic evidence determines referrals and receipt of surgical treatment for both knee and hip patients [74].

The interactions between primary care physicians and their patients matter for increasing access to surgery. Prior discussion of arthroplasty with a physician may favourably influence patients' willingness to undergo surgery. However, women appear to have a lower chance of being referred to secondary care and receiving a specialist's recommendation for TJR. The latter finding merits further study, especially in view of evidence that specialists rely on informal judgment and inference when deciding whether to offer surgery. Moreover, the magnitude of geographical variations in utilisation in England [28] and the United States [75], which persist over many years [75], may not be plausibly explained by corresponding variations in patient preference and need, but appear to be driven by variations in local medical practice associated with differences in established professional opinion [76]. A study of racial and ethnic disparities of knee replacement rates in the United States has estimated that $38 \%$ of the gap of black relative to white women was accounted for by hospital referral region of residence [77].

Despite the inherent uncertainty of surgical decisions and the lack of specific guidelines, patients are regularly given priority for surgery based on their limitations in paid work and caring responsibilities. However, it is not known what relative independent importance these factors have for priority of access, nor their relevance across health systems with varying rates of population health insurance coverage. Research on these issues would help to elucidate the relationship between women's differential use of TJA and gender inequality in the labour market.

The current gaps in evidence suggest the need for a combination of research designs, including observational prospective longitudinal studies in patient cohorts, secondary data analysis of general population surveys of older patients, and experimental preference studies, to investigate the relevant facets of decision making in TJR. Some of these studies are already in progress [78], or may soon follow on the experience of precursors [21,79]. Indeed, much of the existing literature that did not qualify for the present review [80-104] may inform their design. It is worth noting that heterogeneous research methods have hampered the consistent accumulation of evidence, particularly in relation to measuring patient need or severity of disease [105-110] and consequently defining the population of those patients who are able to benefit from surgery. 


\section{Conclusion}

Access to hip and knee arthroplasty is driven by patients' willingness to undergo surgery. In turn, patients' willingness is determined by their knowledge about the technology and their expectations about the outcomes of the procedure, and by local or regional idiosyncratic surgical decision making practice. There is significant variation in patient willingness around the age of retirement from the labour market, but no study has investigated the effects of retirement plans or economic incentives to retire for patients or their partners, on whether or when to undergo an operation. A study is also needed to learn about the difference in the importance of such considerations between men and women. Research on these questions would inform planning to provide for the healthcare needs of an ageing population with a longer working lifespan.

\section{Additional files}

Additional file 1: Appendix: Search Strategy. This appendix presents the electronic search strategy employed to retrieve study records in Medline (Ovid) and Embase.

Additional file 2: Table S1. Characteristics of Included Studies. This table describes the individual studies reviewed, including study year, country, setting, population of subjects, design and follow-up, and measure of need used.

\section{Additional file 3: PRISMA 2009 Checklist.}

Additional file 4: Table S2. Results of Quantitative Studies. This table contains the detailed results presented by individual studies alongside the summary characteristics of the study sample. Readers may refer to this file if they want to learn about the statistical details of the individual study findings.

Additional file 5: Table S3. Disease Specific and Generic Health-Related Quality of Life Outcome Tools). This file presents a summary table describing the health related quality of life tools used by the studies reviewed. This information may help readers to interpret the detailed results in Additional file 4.

Competing interests

The authors declare no competing commercial or non-commercial interests.

\section{Authors' contributions}

RM designed the study and its data collection forms, screened and reviewed studies and extracted the data, and wrote the manuscript. RT contributed to writing the manuscript and its design. OC screened and extracted the data. $J B$ contributed to writing the manuscript. MD contributed to designing the study and writing the manuscript. All authors read and approved the final manuscript.

\footnotetext{
Acknowledgements

The authors gratefully acknowledge funding support from the Institute for Health Technology Studies (InHealth; Washington, DC). The funders had no role in the study design, implementation and writing up of results. The authors accept sole responsibility for the research design implementation, and interpretation of results.

The authors are grateful to Antonieta Medina Lara for her critical review of the manuscript, and detailed suggestions for improvement. They also thank Christine Buttorff for editorial suggestions on an early draft of this paper. All errors remain our sole responsibility.
}

\section{Author details}

'Institute for Health Services Research, University of Exeter, Veysey Building, Salmon Pool Lane, Exeter, EX2 4SG, UK. ${ }^{2}$ Centre for Research in Healthcare Management, Universita Bocconi, Via Roentgen 1, 20136, Milan, Italy. ${ }^{3}$ Johns Hopkins Bloomberg School of Public Health, 624 N. Broadway, Room 689, Baltimore, MD 21205, USA. ${ }^{4}$ Centre for Health Economics, Alcuin 'A' Block, University of York, Heslington, York YO10 5DD, UK.

Received: 20 February 2012 Accepted: 26 June 2012

Published: 30 July 2012

\section{References}

1. Ethgen $O$, Bruyère $O$, Richy $F$, Dardennes $C$, Regisnter JY: Health related quality of life in total hip arthroplasty. A qualitative and systematic review of the literature. J Bone Joint Surg Am 2004, 86 (5):963-974.

2. Tian W, DeJong G, Brown M, Hsieh CH, Zamfirov ZP, Horn SD: Looking upstream: factors shaping demand for postacute joint replacement rehabilitation. Arch Phys Med Rehab 2009, 90:1260-1268.

3. Ibrahim T, Bloch B, Esler CN, Abrams KR, Harper WM: Temporal trends in primary total hip and knee arthroplasty surgery: results from a UK regional register, 1991-2004. Ann R Coll Surg Engl 2010, 92:231-235.

4. March LM, Bagga H: Epidemiology of osteoarthritis in Australia. Med J Aust 2004, 180(5 Suppl):S6-S10.

5. Dixon T, Urquhart DM, Berry P, Bhatia K, Wang Y, Graves S, Cicuttini FM: Variation in rates of hip and knee joint replacement in Australia based on socio-economic status, geographical locality, birthplace and indigenous status. ANZ J Surg 2011, 81:26-31.

6. Agabiti N, Picciotto S, Cesaroni G, Bisanti L, Forastiere F, Onorati R, Pacelli B, Pandolfi P, Russo A, Spadea T, Perucci CA: The influence of socioeconomic status on utilization and outcomes of elective total hip replacement: A multicity population-based longitudinal study. Int I Qual Health C 2007, 19(1):37-44.

7. Katz N: Preferences, quality and the (under) utilization of total joint replacement. Med Care 2001, 39:203-205.

8. Mahomed NN, Barrett J, Katz JN, Baron JA, Wright J, Losina E: Epidemiology of total knee replacement in the United States Medicare population. J Bone Joint Surg Am 2005, 87(6):1222-1228.

9. Cross WW 3rd, Saleh KJ, Wilt TJ, Kane RL: Agreement about indications for total knee arthroplasty. Clin Orthop Relat R 2006, 446:34-39.

10. Dreinhofer KE, Dieppe P, Sturmer T, Grober-Gratz D, Floren M, Gunther KP, Puhl W, Brenner H: Indications for total hip replacement: comparison of assessments of orthopedic surgeons and referring physicians. Ann Rheum Dis 2006, 65:1346-1350.

11. Coyte PC, Hawker G, Croxford R, Attard C, Wright J: Variation in rheumatologists' and family physicians' perceptions of the indication for and outcomes of knee replacement surgery. J Rheumatol 1996, 23:730-738.

12. Tierney WM, Fitzgerald JF, Heck D, Kennedy JM, Katz BP, Melfi CA, Dittus RS, Allen DI, Freund DA, Knee Replacement Patient Outcomes Research Team: Tri-compartmental knee replacement: a comparison of orthopaedic surgeons' self-reported performance rates with surgical indications, contraindications, and expected outcomes. Clin Orthop Relat R 1994, 305:209-217.

13. Mancuso CA, Ranawat CS, Esdaile JM, Johanson NA, Charlson ME: Indications for total hip and total knee arthroplasties. J Arthroplasty 1996, 11:34-46.

14. Wright JG, Coyte P, Hawker G, Bombadier C, Cooke D, Heck D, Dittus R, Freund D: Variation in orthopaedic surgeons' perceptions for and outcomes of knee replacement. Can Med Assoc J 1995, 152:687-697.

15. Mamlin LA, Melfi CA, Parchman ML, Gutierrez B, Allen DI, Katz BP, Dittus RS, Heck DA, Freund DA: Management of osteoarthritis of the knee by primary care physicians. Arch Fam Med 1998, 7:563-567.

16. Clark JP, Hudak PL, Hawker GA, Coyte PC, Mahomed NN, Kreder HJ, Wright JG: The moving target: a qualitative study of elderly patients' decision-making regarding total joint replacement surgery. J Bone Joint Surg Am 2004, 86-A(7):1366-1374.

17. Frankel S, Eachus J, Pearson N, Greenwood R, Chan P, Peters TJ, Donovan J, Davey Smith G, Dieppe P: Population requirement for primary hip-replacement surgery: a cross-sectional study. Lancet 1999, 353(9161):1304-1309. 
18. Zeni JA Jr, Axe MJ, Snyder-Mackler L: Clinical predictors of elective total joint replacement in persons with end-stage knee osteoarthritis. BMC Musculoskel Dis 2008, 11:86.

19. Lievense AM, Koes BW, Verhaar JAN, Bohnen AM, Bierma-Zeinstra SMA Prognosis of hip pain in general practice: a prospective followup study. Arthrit Rheum 2007, 57(8):1368-1374.

20. George LK, Ruiz D, Sloan FA: The effects of total hip arthroplasty on physical functioning in the older population. J Am Geriatr Soc 2008, 56:1057-1062.

21. Hanchate AD, Zhang Y, Felson DT, Ash AS: Exploring the determinants of racial and ethnic disparities in total knee arthroplasty. Med Care 2008, 46(5):481-488.

22. Birrell F, Afzal C, Nahit E, Lunt M, Macfarlane GJ, Cooper C, Croft PR, Hosie G, Silman AJ: Predictors of hip joint replacement in new attenders in primary care with hip pain. Brit J Gen Pract 2003, 53(486):26-30

23. Momohara S, Inoue E, Ikari K, Kawamura K, Tsukahara S, Mochizuki T, Toki H, Miyawaki M, Saito S, Hara M, Kamatani N, Yamanaka H, Tomatsu T: Risk factors for total knee arthroplasty in rheumatoid arthritis. Mod Rheumatol 2007, 17:476-480.

24. McHugh GA, Luker KA: Influences on individuals with osteoarthritis in deciding to undergo a hip or knee joint replacement: A qualitative study. Disabil Rehabil 2009, 31(15):1257-1266.

25. Toye FM, Barlow J, Wright C, Lamb SE: Personal meanings in the construction of need for total knee replacement surgery. Soc Sci Med 2006, 63(1):43-53.

26. Hawker GA, Guan J, Croxford R, Coyte PC, Glazier RH, Harvey BJ, Wright JG, Williams JI, Badley EM: A prospective population-based study of the predictors of undergoing total joint arthroplasty. Arthrit Rheum 2006, 54(10):3212-3220.

27. Conner-Spady B, Sanmartin C, Johnston G, McGurran J, Kehler M, Noseworthy T: Willingness of patients to change surgeons for a shorter waiting time for joint arthroplasty. Can Med Assoc J 2008, 179(4):327-332

28. Judge A, Welton NJ, Sandhu J, Ben-Shlomo Y: Equity in access to total joint replacement of the hip and knee in England: cross sectional study. Brit Med J 2010, 341:c4092.

29. Dunlop DD, Song J, Manheim LM, Chang RW: Racial disparities in joint replacement use among older adults. Med Care 2003, 41(2):288-298.

30. Hawker GA, Wright JG, Coyte PC, Williams JI, Harvey B, Glazier R, Badley EM: Differences between men and women in the rate of use of hip and knee arthroplasty. New Engl J Med 2000, 342(14):1016-1022.

31. Hawker GA, Wright JG, Coyte PC, Williams JI, Harvey B, Glazier R, Wilkins A, Badley EM: Determining the need for hip and knee arthroplasty: the role of clinical severity and patients' preferences. Med Care 2001, 39(3):206-216.

32. Hawker GA, Wright JG, Glazier RH, Coyte PC, Harvey B, Williams JI, Badley EM: The effect of education and income on need and willingness to undergo total joint arthroplasty. Arthrit Rheum 2002, 46(12):3331-3339.

33. Hawker GA, Wright JG, Badley EM, Coyte PC: Perceptions of, and willingness to consider, total joint arthroplasty in a population-based cohort of individuals with disabling hip and knee arthritis. Arthrit Rheum 2004, 51(4):635-641.

34. Sanders C, Donovan JL, Dieppe PA: Unmet need for joint replacement: a qualitative investigation of barriers to treatment among individuals with severe pain and disability of the hip and knee. Rheumatology 2004, 43(3):353-357.

35. Karlson EW, Daltroy LH, Liang MH, Eaton HE, Katz JN: Gender differences in patient preferences may underlie differential utilization of elective surgery. Am J Med 1997, 102(6):524-530.

36. Juni P, Dieppe P, Donovan J, Peters T, Eachus J, Pearson N, Greenwood R, Frankel S: Population requirement for primary knee replacement surgery: a cross-sectional study. Rheumatology 2003, 42(4):516-521.

37. Juni P, Low N, Reichenbach S, Villiger PM, Williams S, Dieppe PA: Gender inequity in the provision of care for hip disease: population-based cross-sectional study. Osteoarthr Cartilage 2010, 18(5):640-645.

38. Steel N, Clark A, Lang IA, Wallace RB, Melzer D: Racial disparities in receipt of hip and knee joint replacements are not explained by need: the Health and Retirement Study 1998-2004. J Gerontol A Biol 2008, 63(6):629-634.

39. Ibrahim SA, Siminoff $L A$, Burant $C J$, Kent-Kwoh C: Variation in perceptions of treatment and self-care practices in elderly with osteoarthritis: A comparison between African American and white patients. Arthrit Care Res 2001, 45(4):340-345.

40. Ibrahim SA, Siminoff LA, Burant CJ, Kwoh CK: Understanding ethnic differences in the utilization of joint replacement for osteoarthritis: the role of patient-level factors. Med Care 2002, 40(1 Suppl):144-51.

41. Ibrahim SA, Siminoff LA, Burant CJ, Kwoh CK: Differences in expectations of outcome mediate African American/white patient differences in "willingness" to consider joint replacement. Arthrit Rheum 2002, 46(9):2429-2435.

42. Lopez JPF, Burant CJ, Siminoff LA, Kwoh CK, Ibrahim SA: Patient perceptions of access to care and referrals to specialists: A comparison of African-American and white older patients with knee and hip osteoarthritis. J Natl Med Assoc 2005, 97(5):667-673.

43. Figaro MK, Williams-Russo P, Allegrante JP: Expectation and outlook: The impact of patient preference on arthritis care among African Americans. J Amb Care Manage 2005, 28(1):41-48.

44. Suarez-Almazor ME, Souchek J, Kelly PA, O'Malley K, Byrne M, Richardson M, Pak C: Ethnic variation in knee replacement: patient preferences or uninformed disparity? Arch. Intern Med 2005, 165(10):1117-1124.

45. Suarez-Almazor ME, Richardson M, Kroll TL, Sharf BF: A qualitative analysis of decision-making for total knee replacement in patients with osteoarthritis. J Clin Rheumatol 2010, 16(4):158-163.

46. Schonberg MA, Marcantonio ER, Hamel MB: Perceptions of physician recommendations for joint replacement surgery in older patients with severe hip or knee osteoarthritis. J Am Geriatr Soc 2009, 57(1):82-88.

47. Card D, Dobkin C, Maestas N: The impact of nearly universal insurance coverage on health care utilization: evidence from Medicare. Am Econ Rev 2008, 98(5):2242-2258.

48. Yong PFK, Milner PC, Payne JN, Lewis PA, Jennison C: Inequalities in access to knee joint replacements for people in need. Ann Rheum Dis 2004, 63:1483-1489.

49. Gooberman-Hill R, Sansom A, Sanders CM, Dieppe PA, Horwood J, Learmonth ID, Williams S, Donovan JL: Unstated factors in orthopaedic decision-making: A qualitative study. BMC Musculoskelet Dis 2010, $11: 213$.

50. Sansom A, Donovan J, Sanders C, Dieppe P, Horwood J, Learmonth I, Williams S, Gooberman-Hill R: Routes to total joint replacement surgery: patients' and clinicians' perceptions of need. Arthrit Care Res 2010, 62(9):1252-1257.

51. Dosanjh S, Matta JM, Bhandari M, Anterior THARC: The final straw: a qualitative study to explore patient decisions to undergo total hip arthroplasty. Arch Orthop Traum Su 2009, 129(6):719-727.

52. Linsell L, Dawson J, Zondervan K, Rose P, Carr A, Randall T, Fitzpatrick R: Population survey comparing older adults with hip versus knee pain in primary care. Brit J Gen Pract 2005, 55(512):192-198.

53. Conner-Spady BL, Johnston GH, Sanmartin C, McGurran J, Noseworthy T: A bird can't fly on one wing: Patient views on waiting for hip and knee replacement surgery. Health Expectat 2007, 10(2):108-116.

54. Birk HO, Henriksen LO: Why do not all hip- and knee patients facing long waiting times accept re-referral to hospitals with short waiting time? Questionnaire study. Health Policy 2006, 77(3):318-325.

55. Borkhoff CM, Hawker GA, Kreder HJ, Glazier RH, Mahomed NN, Wright JG: The effect of patients' sex on physicians' recommendations for total knee arthroplasty. Can Med Assoc J 2008, 178(6):681-687.

56. Borkhoff CM, Hawker GA, Kreder HJ, Glazier RH, Mahomed NN, Wright JG: Patients' gender affected physicians' clinical decisions when presented with standardized patients but not for matching paper patients. J Clin Epidemiol 2009, 62(5):527-541.

57. Quintana JM, Azkarate J, Goenaga Jl, Arostegui I, Beldarrain I, Villar JM: Evaluation of the appropriateness of hip joint replacement techniques. Int J Technol Assess 2000, 16(1):165-177.

58. Escobar A, Quintana JM, Azkarate J, Guenaga JI, Arenaza JC, Garai I: Development of explicit criteria for total knee replacement. Int J Technol Assess 2003, 19(1):57-70.

59. Quintana JM, Escobar A, Arostegui I, Bilbao A, Azkarate J, Goenaga J, Arenaza JC: Health-related quality of life and appropriateness of knee or hip joint replacement. Arch Intern Med 2006, 166(2):220-226.

60. Boutron I, Rannou F, Jardinaud-Lopez M, Meric G, Revel M, Poiraudeau S: Disability and quality of life of patients with knee or hip osteoarthritis in the primary care setting and factors associated with general 
practitioners' indication for prosthetic replacement within 1 year. Osteoarthr Cartilage 2008, 16(9):1024-1031.

61. Johnson SA, Kalairajah Y, Moonot P, Steele N, Field RE: Fast-track assessment clinic: Selection of patients for a one-stop hip assessment clinic. Ann Roy Coll Surg 2008, 90(3):208-212.

62. Allepuz A, Espallargues M, Moharra M, Comas M, Pons JMV: Prioritisation of patients on waiting lists for hip and knee arthroplasties and cataract surgery: Instruments validation. BMC Health Serv Res 2008, 8:76.

63. Derrett S, Paul C, Herbison P, Williams H: Evaluation of explicit prioritisation for elective surgery: A prospective study. $J$ Health Serv Res Pol 2002, 7(SUPPL. 1):14-22.

64. Derrett S, Devlin N, Hansen P, Herbison P: Prioritizing patients for elective surgery: A prospective study of clinical priority assessment criteria in New Zealand. Int J Technol Assess Health Care 2003, 19(1):91-105.

65. De Coster C, McMillan S, Brant R, McGurran J, Noseworthy T, Cave A, Dawyduk B, Findlay T, Hall W, Hilderman T, Hurlburt M, Mazowita G, Miller A, Vaughan G: The Western Canada Waiting List Project: Development of a priority referral score for hip and knee arthroplasty. J Eval Clin Pract 2007, 13(2):192-197.

66. The Primary Care Rheumatologic Society: The management of osteoarthritis. Guidelines 1999, 8:301-303.

67. Blake VA, Allegrante JP, Robbins L, Mancuso CA, Peterson MGE, Esdaile JM, Paget SA, Charlson ME: Racial differences in social network experience and perceptions of benefit of arthritis treatments among New York city Medicare beneficiaries with selfreported hip and knee pain. Arthrit Care Res 2002, 47(4):366-371.

68. Katz N: Preferences, quality and the (under) utilization of total joint replacement. Med Care 2001, 39:203-205.

69. Strumpf E: Employer-sponsored health insurance for early retirees: impacts on retirement, health and health care. Int J Health Care Finance Econ 2010, 10:105-147.

70. Grossman M: On the concept of human capital and the demand for health. J Polit Econ 1972, 80(2):223-255.

71. Mitchell JM, Hadley J, Gaskin DJ: Physicians' responses to Medicare fee schedule reductions. Med Care 2000, 38(10):1029-1039.

72. Friedman B, Elixhauser A: The changing distribution of a major surgical procedure across hospitals: were supply shifts and disequilibrium important? Health Econ 1995, 4(4):301-314.

73. Tarrant M, Butler K: Effects of self-categorization on orientation towards health. Brit J Soc Psychol 2010, 50:121-139.

74. Bedson J, Jordan K, Croft P: How do GPs use x-rays to manage chronic knee pain in the elderly? A case study. Ann Rheum Dis 2003, 62:450-454

75. Weinstein JN, Bronner KK, Shawver Morgan T, Wennberg JE: Trends and geographic variations in major surgery for degenerative diseases of the hip, knee and spine. Is there a roadmap for change? Health Affair 2004, doi:10.1377/hlthaff.var.81.

76. Wennberg: Commentary: A debt of gratitude to J. Alison Glover. Int J Epidemiol 2008, 37:26-29.

77. Skinner J, Weinstein JN, Sporer SM, Wennberg JE: Racial, ethnic and geographic disparities in rates of knee arthroplasty among Medicare patients. New Engl J Med 2003, 349:1350-1359.

78. Riddle DL, Kong X, Jiranek WA: Two-year incidence and predictors of future knee arthroplasty in persons with symptomatic knee osteoarthritis: preliminary analysis of longitudinal data from the osteoarthritis initiative. Knee 2009, 16(6):494-500.

79. Cross MJ, March LM, Lapsley HM, Tribe KL, Brnabic AJ, Courtenay BG, Brooks PM: Determinants of willingness to pay for hip and knee joint replacement surgery for osteoarthritis. Rheumatology 2000, 39(11):1242-1248.

80. Tennant A, Fear J, Pickering A, Hillman M, Cutts A, Chamberlain MA: Prevalence of knee problems in the population aged 55 years and over: identifying the need for knee arthroplasty. Brit Med J 1995, 310(6990):1291-1293.

81. Ang DC, Tahir N, Hanif $\mathrm{H}$, Tong $\mathrm{Y}$, Ibrahim SA: African Americans and Whites are equally appropriate to be considered for total joint arthroplasty. J Rheumatol 2009, 36(9):1971-1976.

82. Judge A, Welton NJ, Sandhu J, Ben-Shlomo Y: Modeling the need for hip and knee replacement surgery. Part 1. A two-stage cross-cohort approach. Arthrit Rheum-Arth 2009, 61(12):1657-1666.
83. Judge A, Welton NJ, Sandhu J, Ben-Shlomo Y: Modeling the need for hip and knee replacement surgery. Part 2. Incorporating census data to provide small-area predictions for need with uncertainty bounds. Arthrit Rheum-Arth 2009, 61(12):1667-1673.

84. Steel N, Melzer D, Gardener E, McWilliams B: Need for and receipt of hip and knee replacement-a national population survey. Rheumatology 2006, 45(11):1437-1441.

85. Fear J, Hillman M, Chamberlain MA, Tennant A: Prevalence of hip problems in the population aged 55 years and over: access to specialist care and future demand for hip arthroplasty. Brit J Rheumatol 1997, 36(1):74-76.

86. Milner PC, Payne JN, Stanfield RC, Lewis PA, Jennison C, Saul C: Inequalities in accessing hip joint replacement for people in need. Europ. J. Publ. Health. 2004, 14(1):58-62.

87. Kingston R, Carey M, Masterson E: Need-based waiting lists for hip and knee arthroplasty. Irish J Med Sci 2000, 169(2):125-126.

88. Birrell F, Johnell O, Silman A: Projecting the need for hip replacement over the next three decades: influence of changing demography and threshold for surgery. Ann Rheum Dis 1999, 58(9):569-572.

89. Aiken $A B$, Harrison MM, Atkinson M, Hope J: Easing the burden for joint replacement wait times: the role of the expanded practice physiotherapist. Healthcare Quart 2008, 11(2):62-66.

90. Byrne MM, O'Malley KJ, Suarez-Almazor ME: Ethnic differences in health preferences: analysis using willingness-to-pay. J Rheumat 2004, 31(9):1811-1818.

91. Olsen JA, Donaldson C: Helicopters, hearts and hips: using willingness to pay to set priorities for public sector health care programmes. Soc Sci Med 1998, 46(1):1-12.

92. Tuominen R: Evaluation of three methods assessing the relative value of a dental program. Acta Odontol Scand 2008, 66(2):82-87.

93. Crawford BM, Meana M, Stewart D, Cheung AM: Treatment decision making in mature adults: gender differences. Health Care Women Int 2000, 21(2):91-104

94. Mitchell HL, Hurley MV: Management of chronic knee pain: a survey of patient preferences and treatment received. BMC Musculoskel Dis 2008, 9:123.

95. Dominick KL, Ahern FM, Gold CH, Heller DA: Health-related quality of life and health service use among older adults with osteoarthritis. Arthrit Rheum 2004, 51(3):326-331.

96. Loza E, Abasolo L, Clemente D, Lopez-Gonzalez R, Rodriguez L, Vadillo C, Fernandez-Gutierrez B, Macarron P, Jover JA, Hernandez-Garcia C: Variability in the use of orthopedic surgery in patients with rheumatoid arthritis in Spain. J Rheumatol 2007, 34(7):1485-1490.

97. Wright JG, Rudicel S, Feinstein AR: Ask patients what they want: Evaluation of individual complaints before total hip replacement. J Bone Joint Surg Brit 1994, 76(2):229-234.

98. Wright JG, Hawker GA, Bombardier C, Croxford R, Dittus RS, Freund DA, Coyte PC: Physician enthusiasm as an explanation for area variation in the utilization of knee replacement surgery. Med Care 1999, 37(9):946-956.

99. Braddock lii C, Hudak PL, Feldman JJ, Bereknyei S, Frankel RM, Levinson W: "Surgery is certainly one good option": Quality and time-efficiency of informed decision-making in surgery. J Bone Joint Surg Am 2008, 90(9):1830-1838.

100. MacKay C, Davis AM, Mahomed N, Badley EM: Expanding roles in orthopaedic care: a comparison of physiotherapist and orthopaedic surgeon recommendations for triage. J Eval Clin Pract 2009, 15(1):178-183.

101. Propper C, Eachus J, Chan P, Pearson N, Smith GD: Access to health care resources in the UK: the case of care for arthritis. Health Econ 2005, 14:391-406.

102. Van Walraven C, Paterson JM, Kapral M, Chan B, Bell M, Hawker G, Gollish J, Schatzker J, Williams JI, Naylor CD: Appropriateness of primary total hip and knee replacements in regions of Ontario with high and low utilization rates. Can Med Assoc J 1996, 155(6):697-706.

103. Dent TH, Cunningham SL, Hook WE, Morris RJ, Sylvester NC: The MODEL project: a scoring system to manage demand for cataract and joint replacement surgery. Brit J Gen Pract 2001, 51(472):917-919.

104. Chappell GE Jr: Current trends in the treatment of the young adult with disabling hip disease. A survey. Clin Orthop Relat Res 1975, 106:35-40.

105. Bellamy N, Buchanan WW, Goldsmith CH, Campbell J, Stitt L: Validation study of WOMAC: a health status instrument for measuring 
clinically-important patient-relevant outcomes following total hip or knee arthroplasty in osteoarthritis. J Orthop Rheumatol 1988, 1:95-108.

106. Hadorn DC, Holmes AC: The New Zealand priority criteria project. Part 1: overview. Brit Med J 1997, 314:131-4.

107. Lequesne MG, Mery C, Samson M, Gerard P: Indexes of severity for osteoarthritis of the hip and knee: validation-value in comparison with other assessment tests. Scand J Rheumatol 1987, 65:85-89.

108. Dawson J, Fitzpatrick R, Murray D, Carr A: Questionnaire on the perceptions of patients about total hip replacement. J Bone Joint Sur-Br 1996, 78-B:185-190.

109. The Eurogol Group: Euroqol -a new facility for the measurement of health-related quality-of-life. Health Policy 1990, 16:199-208.

110. Ware JE, Sherbourne CD: The MOS 36-item Short-Form Health Survey (Sf-36): I Conceptual framework and item selection. Med Care 1992, 30:473-483

doi:10.1186/1472-6963-12-225

Cite this article as: Mújica Mota et al.: Determinants of demand for total hip and knee arthroplasty: a systematic literature review. BMC Health Services Research 2012 12:225.

\section{Submit your next manuscript to BioMed Central and take full advantage of:}

- Convenient online submission

- Thorough peer review

- No space constraints or color figure charges

- Immediate publication on acceptance

- Inclusion in PubMed, CAS, Scopus and Google Scholar

- Research which is freely available for redistribution 